\title{
Crystallization Kinetics and Physical Properties of Al-3Fe-3Ni Alloy Due to the Order of the Introduction of the Alloying Elements
}

ISSN: 2576-8840

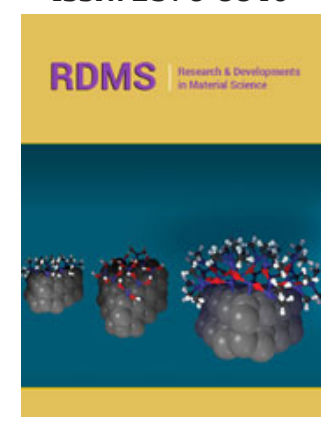

*Corresponding author: Maksymchuk IM, IM Frantsevich Institute for Problems of Materials Science, NAS of Ukraine, Ukraine

Submission: 侢 March 18, 2020

Published: 眥April 03, 2020

Volume 13 - Issue 1

How to cite this article: Maksymchuk I, Khriplyviy A, Frieze V, Romanko P, Khokhlova J. Crystallization Kinetics and Physical Properties of Al-3Fe-3Ni Alloy Due to the Order of the Introduction of the Alloying Elements. Res Dev Material Sci. 13(1).RDMS.000804.2020.

DOI: 10.31031/RDMS.2020.13.000804

Copyright@ Maksymchuk IM, This article is distributed under the terms of the Creative Commons Attribution 4.0 International License, which permits unrestricted use and redistribution provided that the original author and source are credited.

\author{
Maksymchuk IM ${ }^{1 *}$, Khriplyviy $\mathrm{AO}^{1}$, Frieze $\mathrm{VV}^{1}$, Romanko PM${ }^{1}$, Khokhlova $\mathrm{JA}^{2}$ \\ and Khokhlov MA ${ }^{2}$ \\ ${ }^{1}$ IM Frantsevich Institute for Problems of Materials Science, NAS of Ukraine, Ukraine \\ ${ }^{2}$ EO Paton Electric Welding Institute, NAS of Ukraine, Ukraine
}

\begin{abstract}
The specific features of the crystallization kinetics of the ternary Al-Ni-Fe system due to the order of the introduction of the alloying elements are explained in terms of the cluster structure of the melts of binary metal systems Al-Ni and Al-Fe. It was established that the order of introduction of the alloying elements into the aluminum melt determines the formation of a different cluster structure, which is responsible for the mechanism of formation of crystallization nuclei and the formation of the phase composition of alloys. It is assumed that a substantial supersaturation of the solid solution with nickel atoms is associated with the introduction of Al3Ni-type clusters into the aluminum matrix of the Al-3Ni-3Fe alloy. This concept is confirmed by the presence of two exothermic peaks on the DSC curves in the region before the crystallization of the alloy and explains the abnormally high value of Young's modulus and the high yield stress of the alloy.
\end{abstract}

Keywords: Crystallization kinetics; Cluster structure of the melt; Thermographic analysis; Young's modulus

\section{Introduction}

Alloys of the Al-Fe-Ni system are widely used in engineering due to their good fluidity, corrosion resistance, heat resistance, and their electrophysical properties [1,2], and also as magnetic materials and in shape-memory devices [3-6]. In this regard, this system of alloys is fairly well studied both scientifically and technologically. The authors of work [7] studied the effect of the cooling rate on the microstructure and hardness of the Al-1.0Fe-1.0Ni alloy during directed crystallization. They established the relationship between the cooling rate, the formation of the microstructure, hardness and the distance between the eutectic phase. Powder metallurgy methods and the process of rapid solidification were also used to form a specific morphology of the bulk eutectic phase $[8,9]$.

Modern ideas about the structure of metal melts are based on cluster models, such as atomic groups with a certain short-range order (spatial ordering), confirmed by numerous studies using X-ray, electron and neutron analysis, NMR, electrical resistance, internal friction/ viscosity, etc. [10-13]. The cluster structure of the liquid state affects the nucleation of crystals and is manifested in the features of the kinetics of crystallization and, as a result, determines the final structure, phase composition, and physic-mechanical properties of metal alloys. In this regard, structural transformations in metal melts and cluster models in liquid physics in recent years have been the subject of intensive research in related areas of metallurgy, physical chemistry, metal physics, and physical materials science. Thus, works $[12,13]$ were devoted to the study of the local atomic ordering of binary Al-Fe and Al-Ni melts. However, the influence of the cluster structure of the melt of the ternary system on the crystallization kinetics, phase composition, and properties has not been studied sufficiently. Therefore, the aim of this work is a comparative analysis of the crystallization features of $\mathrm{Al}-3 \mathrm{Fe}$ and $\mathrm{Al}-$ $3 \mathrm{Ni}$ binary systems and $\mathrm{Al}-3 \mathrm{Fe}-3 \mathrm{Ni}$ and $\mathrm{Al}-3 \mathrm{Ni}-3 \mathrm{Fe}$ alloys, as well as the formation of their 
microstructure and mechanical properties caused by the order of introduction of alloying elements in the ternary system.

\section{Methodology}

$\mathrm{Al}-3 \mathrm{Fe}$ and $\mathrm{Al}-3 \mathrm{Ni}$ alloys and $\mathrm{Al}-3 \mathrm{Fe}-3 \mathrm{Ni}$ and $\mathrm{Al}-3 \mathrm{Ni}-3 \mathrm{Fe}$, AK-7 alloys with 4 wt.\% Fe were smelted in a smelter with resistive heating in argon medium from $99.99 \%$ pure Al. The melt temperature was controlled and maintained with an accuracy of $\pm 1^{\circ} \mathrm{C}$. The temperature of the superheat and the spill of the melt was $850{ }^{\circ} \mathrm{C}$. To completely dissolve the alloying elements, the melt was intensively stirred for 15 minutes after each x170 mm.

The temperatures of the various crystallization stages were fixed using a chromel - alumel thermocouple introduced into the melt to a depth of $\sim 3 \mathrm{~mm}$ through the crystallizer body. The characteristics of the thermosensitive element provide very low inertia of the thermocouple when measuring the temperature of the medium. The te introduction of impurities. The melt was poured into a massive copper mold with dimensions of $70 \times 60$ mperature value was recorded using a hardware-software computerized complex in real-time, allowing us to record 500 values per $1 \mathrm{sec}$. In order to exclude the thermal noise of the thermocouple, the initial curve (an array of 30,000 points) was pre-processed (smoothed) by the method of averaging using the graphic pack "Origin 7.5".

X-ray diffraction experiments were performed on a DRONUM1 diffractometer in monochromatic $\mathrm{Cu}-\mathrm{K} \alpha$ radiation. Graphite monocrystal was used as a monochromator. Diffractograms were recorded by the step scanning method in the $10-120^{\circ}$ range of $2 \Theta$ angles. The scanning step was $0.05^{\circ}$ with an exposure time of 3-9sec. Data processing was carried out using the Powder Cell 2.4 program for the full-profile analysis of x-ray spectra from a mixture of polycrystalline phase components. Studies of melting and crystallization processes of prototypes were carried out using a STA 449F1 synchronous thermal analyzer from NETZSCH, Germany at a heating and cooling rate of $20^{\circ} \mathrm{C} / \mathrm{min}$. Mechanical tensile tests were carried out on a 1246P-2/2300 machine of the NIKIMP design using cylindrical samples with a diameter of $3 \mathrm{~mm}$ and a working part length of $l_{0} \approx 18.5 \mathrm{~mm}$ at a strain rate of $10^{-3} \mathrm{~s}^{-1}$ in accordance with DSTU EN 10002-1: 2006 at room temperature. The engineering strain was fixed with a strain gauge directly from the working part of the sample. Vickers hardness was measured on a hardness tester HPO-250 under $5 \mathrm{~kg}$ load.

\section{Results}

A comparative analysis of the sequence of phase transformations, the establishment of temperature and time intervals, as well as the features of crystallization of eutectic alloys, was carried out by comparing the results of direct thermal analysis of the kinetics of crystallization. This approach turned out to be effective and made it possible to establish a number of patterns of crystallization of the Mg-Al-Ca-Ti alloy $[14,15]$ under the influence of electrohydropulse and magnetoimpulse treatment of the melt during AK7 crystallization [16]. Figure $1 \& 2$ show thermograms of crystallization of the Al-3Fe alloy obtained under identical cooling conditions. The melt cooling rate before crystallization began was
$50{ }^{\circ} \mathrm{C} / \mathrm{s}$. For a more accurate graphical determination of time and temperature intervals, as well as characteristic points, we used the first time derivative of temperature in coordinates dT/dt-T (Figure 3 \& 4). DSC crystallization curves of Al-3Fe-3Ni and Al-3Ni3Fe alloys are shown in Figure 5. Measured mechanical properties and Vickers hardness of the alloys are given in the Table 1 . The microstructure of the alloys is shown in Figure 6.

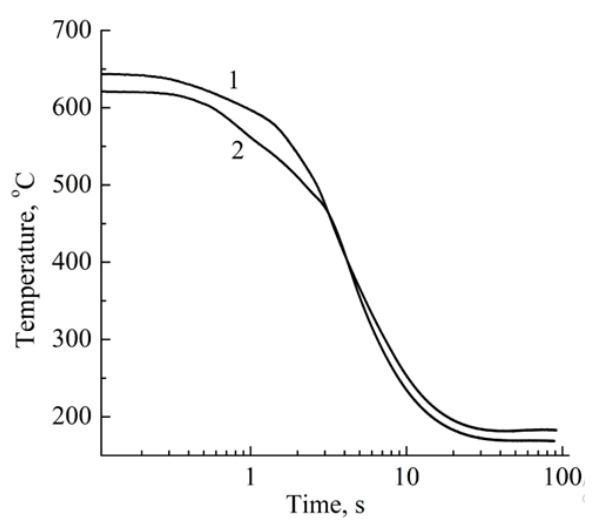

Figure 1:Cooling curves for Al-3Fe (1) -and Al-3Ni (2) melts.

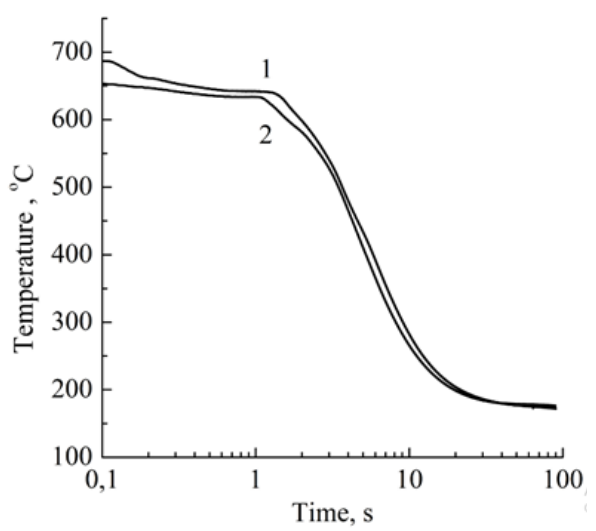

Figure 2:Cooling curves for Al-3Fe-3Ni (1) and Al$3 \mathrm{Ni}-3 \mathrm{Fe}(2)$ melts.

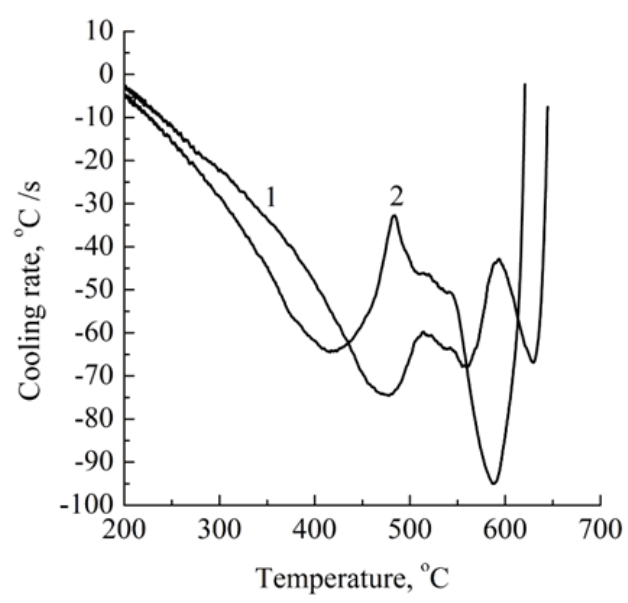

Figure 3:Cooling rate curves for Al-3Fe (1) and Al$3 \mathrm{Ni}(2)$ melts. 


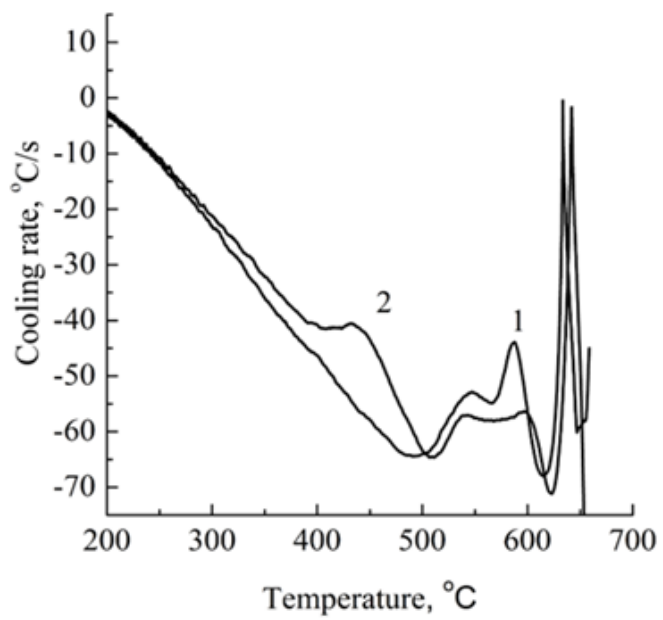

Figure 4:Cooling rate curves for $\mathrm{Al}-3 \mathrm{Fe}-3 \mathrm{Ni}(1)$ and Al-3Ni-3Fe (2) melts.

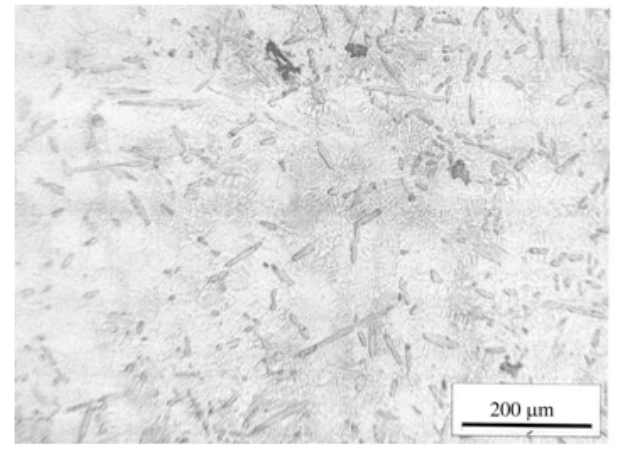

(a)

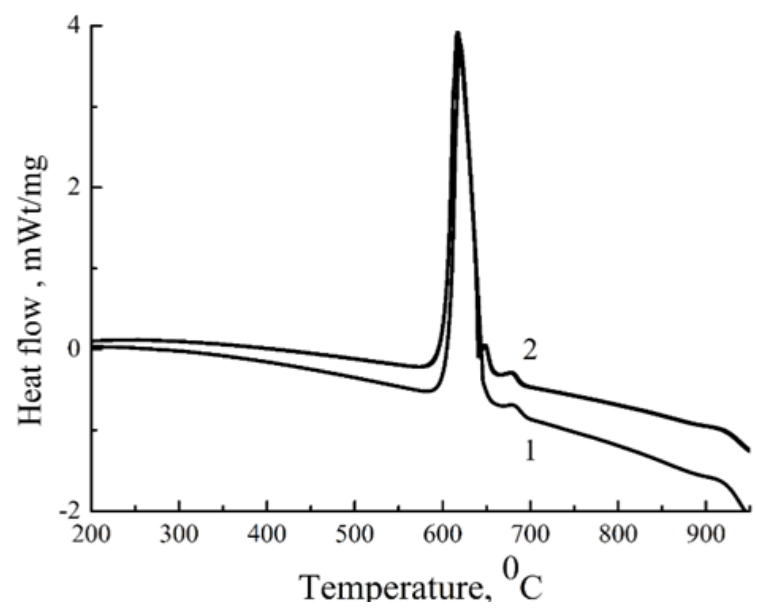

Figure 5:DSC crystallization curves for Al-3Fe-3Ni (1) and Al-3Ni-3Fe (2) alloys.

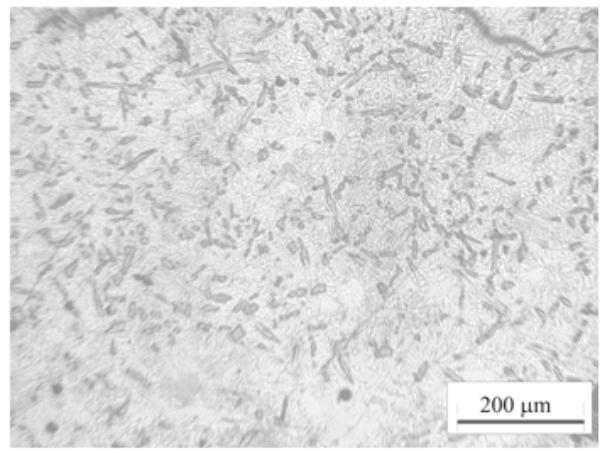

(b)

Figure 6:Microstructure of Al-3Ni-3Fe (a) and Al-3Fe-3Ni (b) alloys.

Table 1: Properties of Al-3Fe-3Ni and Al-3Ni-3Fe alloys

\begin{tabular}{|c|c|c|c|c|c|}
\hline \multirow{2}{*}{ Alloy } & \multicolumn{4}{|c|}{ Mechanical Properties } & Vickers Hardness, Hv, \\
MPa & Tensile Strength, MPa & $\begin{array}{c}\text { Yield Strength, } \\
\text { MPa }\end{array}$ & Engineering Strain, \% & $\begin{array}{c}\text { Young's Modulus, } \\
\text { GPa }\end{array}$ & $\begin{array}{c}\text { Va, } \\
\text { Al-3Fe-3Ni }\end{array}$ \\
\cline { 2 - 6 } & 144,0 & 58,0 & 5,5 & 70,7 & 500 \\
\hline Al-3Ni-3Fe & 142,5 & 71,0 & 4,5 & 86,0 & 510 \\
\hline
\end{tabular}

\section{Discussion}

State diagrams and phase equilibria of binary and ternary aluminum systems with iron and nickel have been studied in a large number of works [for example monograph [17]], while the structure of liquid melts from the point of view of local atomic ordering and its effect on the crystallization process, microstructure formation and properties of alloys are still insufficiently studied even for binary systems.

In works [12,13], the atomic structure of liquid Fe-Al alloys was studied by X-ray diffraction and viscosity measurements. It was shown that all the studied melts of the Fe-Al system are microinhomogeneous and contain atomic micro formations (clusters), which differ in composition and atomic packing. There are four types of clusters, two of which contain atoms of the same kind (Fe or $\mathrm{Al}$ ); the composition of two other types of clusters is similar to ordering in stoichiometric solid phases $\mathrm{Fe}_{2} \mathrm{Al}_{5}$ and $\mathrm{Fe}_{3} \mathrm{Al}$. Changes in concentrations of components in Fe-Al alloys lead to a change in the volume fraction of each type of cluster, while the atomic composition and arrangement of atoms inside the clusters remain constant. 
The studies of structure in liquid alloys of Al-Ni system were carried in works [18-24]. The authors note a short-range ordering with the formation of $\mathrm{Al}-\mathrm{Ni}$ clusters, the size, and distance between atoms depends on the temperature and concentration of nickel in the melt. The analysis of the dependence of viscosity on $\mathrm{Ni}$ concentration at a temperature of $800{ }^{\circ} \mathrm{C}$ shows that $\mathrm{Al}_{3} \mathrm{Ni}$-type clusters are formed in the region above 1.5 at.\% [24].

In accordance with the data of work [18], the melt overheating temperature was chosen at $850^{\circ} \mathrm{C}$, which at a nickel concentration of 3 wt.\% is sufficient for the formation of $\mathrm{Al}_{3} \mathrm{Ni}$ and $\mathrm{Fe}_{3} \mathrm{Al}$ clusters. As seen from Figure 3, crystallization of the Al-3Fe alloy has a pronounced two-stage character and begins at $630{ }^{\circ} \mathrm{C}$, which is $42{ }^{\circ} \mathrm{C}$ earlier than the beginning of crystallization of the $\mathrm{Al}-3 \mathrm{Ni}$ alloy. Thus the crystallization interval of the first alloy $\left(155^{\circ} \mathrm{C}\right)$ is $20^{\circ} \mathrm{C}$ less, and the solidification process takes place with a higher average speed $\left(60{ }^{\circ} \mathrm{C}\right.$ and $50{ }^{\circ} \mathrm{C}$, respectively). From this, it can be concluded that the $\mathrm{Fe}$ and $\mathrm{Al}$ atoms interact more strongly, which at a given melt temperature indicates an energetically less favorable formation of $\mathrm{Al}_{3} \mathrm{Ni}$-type clusters, their transformation (growth) into crystallization nuclei, and a significant supercooling of the melt is required for this process to occur. Unlike binary systems, the curves of the cooling rate of the melts of ternary systems (Figure 4) show distinct peaks in the range of $620-650{ }^{\circ} \mathrm{C}$, which correspond to the formation and growth of eutectic crystallization nuclei. From a comparison of Figure 3, curve 1 and Figure 4 it can be seen that the temperature at which crystallization of ternary alloys begins is weakly dependent on the order of introduction of alloying elements and is closer to the temperature at which crystallization of the Al$3 \mathrm{Fe}$ alloy begins. At the same time, the crystallization of the $\mathrm{Al}$ $3 \mathrm{Fe}-3 \mathrm{Ni}$ alloy occurs in the range of $123{ }^{\circ} \mathrm{C}$ and its character is similar to the crystallization of the binary $\mathrm{Al}-3 \mathrm{Fe}$ system, while the crystallization of the $\mathrm{Al}-3 \mathrm{Ni}-3 \mathrm{Fe}$ alloy corresponds to a wider range of $220{ }^{\circ} \mathrm{C}$. In this case, the average crystallization rate practically does not differ and amounts to $55^{\circ} \mathrm{C} / \mathrm{s}$. From this, we can conclude that the kinetics of crystallization of the ternary system, at least at the initial stage, is due to the formation of nuclei based on $\mathrm{Fe}_{3} \mathrm{Al}$ clusters, which, according to [17], can dissolve up to 3-4 wt.\% $\mathrm{Ni}$, while $\mathrm{Al}_{3} \mathrm{Ni}$-type clusters dissolve less than $1 \mathrm{wt} . \% \mathrm{Ni}$. Therefore, when $\mathrm{Fe}$ is introduced first, $\mathrm{Fe}_{3} \mathrm{Al}$ type clusters are formed, which are able to completely dissolve nickel and transform into eutectic crystallization nuclei of the $\mathrm{Al}_{9}(\mathrm{Ni}, \mathrm{Fe})_{2}$ type. This also explains the presence of the third low-temperature stage of crystallization of the $\mathrm{Al}-3 \mathrm{Ni}-3 \mathrm{Fe}$ alloy (with the introduction of the Ni first) in the range of $400-490{ }^{\circ} \mathrm{C}$, when additional temperature reduction and additional time are necessary for the conversion of $\mathrm{Al}_{3} \mathrm{Ni}$-type clusters to crystallization nuclei. Moreover, in the temperature range of the previous eutectic crystallization on the DSC curves of the Al-3Ni3Fe alloy (Figure 5, curve 2), two exothermic peaks are observed, while only one peak precedes the crystallization of the $\mathrm{Al}-3 \mathrm{Fe}-3 \mathrm{Ni}$ alloy. Obviously, these thermal effects correspond to the formation of crystallization nuclei in the melt by the cluster mechanism, which confirms the outlined ideas. These features of the crystallization kinetics of ternary systems are manifested in the formation of the microstructure (Figure 6) and phase composition of the alloy. A narrower crystallization interval of the first alloy promoted the formation of more dispersed particles of this phase (Figure 6). According to X-ray diffractometry data, the alloy contains the $\mathrm{Al}_{9} \mathrm{Fe}_{1.7} \mathrm{Ni}_{0.3}$ phase, with the volume fraction of the phase in the $\mathrm{Al}$ $3 \mathrm{Fe}-3 \mathrm{Ni}$ alloy being $10.5 \%$, whereas when nickel is introduced first it is significantly less $-6.73 \%$. The difference in phase composition caused a different concentration of alloying elements in the solid solution. A local X-ray spectral analysis showed that when nickel is introduced first, its concentration in the solid solution is $2.7 \mathrm{wt} . \%$, which is higher than when iron is introduced first - 1.9 wt.\%. The concentration of iron atoms in the alloys differs insignificantly 1.11.2 wt.\%. A high nickel concentration may be due to the fact that part of the $\mathrm{Al}_{3} \mathrm{Ni}$ and, to a lesser extent, $\mathrm{Fe}_{3} \mathrm{Al}$ type clusters are not involved in the formation of new phase nuclei, but are introduced into the solid solution under conditions of nonequilibrium crystallization. This assumption is confirmed by the fact that the lattice parameter of aluminum is $4.049 \AA$ and is close to its value for pure metal $4.050 \AA$ A.

As can be seen from the table, the strength, plasticity and hardness of the alloys differ insignificantly, however, the yield strength and Young's modulus, physical qualities characterizing the state of the dislocation-impurity system and the nature of the interatomic interaction are significantly higher for the $\mathrm{Al}-3 \mathrm{Ni}-3 \mathrm{Fe}$ alloy. Moreover, DSC analysis showed that upon repeated slow crystallization of the $\mathrm{Al}-3 \mathrm{Ni}-3 \mathrm{Fe}$ alloy superheated to $1000{ }^{\circ} \mathrm{C}$ in the temperature range of the preceding eutectic crystallization, two peaks are observed on the curve, which correspond to the formation of ternary phase nuclei by the cluster mechanism described above. It is known [25] that even small nickel additives significantly impair the amorphization ability of aluminum-based alloys with iron, which is manifested in the presence of Al-Ni clusters in amorphous materials, which subsequently transform into nuclei of the metastable decagonal quasicrystalline phase [26]. Accordingly, we can assume that the abnormally high values of Young's modulus are explained either by the presence of a nanoscale triple metastable decagonal quasicrystalline phase, which is formed as a result of diffusion flows initiated by elastic distortions of the lattice under loading, or by the formation of nanoscale cluster compounds with a short-range order similar to ordering of the intermetallic $\mathrm{Al}_{9}(\mathrm{Ni}, \mathrm{Fe})_{2}$ phase. Obviously, more research is needed to determine the preferred hardening mechanism of this alloy.

\section{Conclusion}

A comparative analysis of crystallization thermograms of binary $\mathrm{Al}-3 \mathrm{Fe}$ and $\mathrm{Al}-3 \mathrm{Ni}$ and ternary $\mathrm{Al}-3 \mathrm{Fe}-3 \mathrm{Ni}$ and $\mathrm{Al}-3 \mathrm{Ni}-3 \mathrm{Fe}$ alloys from the standpoint of the cluster model of the structure of liquid metal melts made it possible to explain the specific features of the crystallization kinetics of these objects under conditions of rapid cooling. Since the order of introduction of alloying elements does not affect the initial crystallization temperature of the ternary system, and it corresponds to the temperature of the beginning of crystallization of the Al-3Fe alloy, we can conclude that the formation of ternary phase nuclei occurs on the basis of $\mathrm{Fe}_{3} \mathrm{Al}$-type clusters. This conclusion confirms the narrow temperature range of crystallization of the Al-3Fe-3Ni alloy. 
Iron and nickel belong to metallic impurities that are poorly soluble in aluminum; their concentration in a solid solution of aluminum, depending on its purity, can vary from hundredths to tenths of a percent. At the same time, the concentrations of these elements observed in the solid solution significantly exceed the equilibrium values for binary systems, while the lattice parameter of the aluminum matrix practically corresponds to the value for pure aluminum. Consequently, it can be assumed that there are local nanoscale regions beyond the sensitivity of X-ray diffractometry, in which the concentrations of iron and nickel (especially) atoms exceed the equilibrium one. Since melts of binary systems are prone to the formation of heterogeneous clusters, it is logical to assume that it is these objects that are introduced into the aluminum solid solution in the case of crystallization of the ternary system. This conclusion is confirmed by DSC analysis of crystallization of the $\mathrm{Al}-3 \mathrm{Ni}-3 \mathrm{Fe}$ alloy, when two exothermic peaks corresponding to the formation of ternary phase nuclei based on two types of clusters are observed in the eutectic pre-crystallization region. This manifests the effect of "genetic heredity" of atomic ordering in clusters in the melt and clusters in solid solution. It should be emphasized that on the DSC crystallization curves of the Al-3Fe-3Ni alloy, we observe only one exothermic peak corresponding to the formation of ternary phase nuclei, based on clusters that probably contain atoms of all three elements. The ideas presented in the article about the specific features of the crystallization kinetics explain not only the differences in the phase composition of the alloys (volume fraction of the $\mathrm{Al}_{9} \mathrm{Fe}_{1.7} \mathrm{Ni}_{0.3}$ phase), but also the abnormally high Young's modulus of the Al-3Ni-3Fe alloy.

\section{References}

1. Zhang L, Du Y, Xu H, Tang CY, Chen HL, et al. (2008) Phase equilibria of the Al-Fe-Ni system at $850^{\circ} \mathrm{C}$ and $627^{\circ} \mathrm{C}$. J Alloys Compd 454: 129-135.

2. Kim JM, Yun HS, Shin JS, Kim KT, Ko SH (2015) Mold filling ability and hot cracking susceptibility of Al-Fe-Ni alloys for high conductivity applications. J Teknol 75: 71-77.

3. Marcon G, Lay S (2000) Equilibrium phases in the miscibility gap of the $\mathrm{Fe}-\mathrm{Ni}$-Al system in connection with the physical properties of the alloys. Ann Chim Sci Mat 25: 21-40.

4. Bitterlich H, Löser W, Schultz L (2002) Reassessment of Ni-Al and Ni-FeAl solidus temperatures. J Phase Equilibr 23: 301-304.

5. Hao SM, Ishida K, Nishizawa T (1985) Role of alloying elements in phase decomposition in Al-Ni-Co magnet alloys. Metall. Trans A16:179-185.

6. Ono N, Tsukahara A, Kainuma R, Ishida K (1999) The properties of twophase Ni-Al-Fe shape memory alloys in the virgin and shape-memorycycled states. Mater Sci Eng A 273: 420-424.

7. Canté MV, Brito C, Spinelli JE, Garcia A (2013) Interrelation of cell spacing, intermetallic compounds and hardness on a directionally solidified Al-1.0Fe-1.0Ni alloy. Mater Des 51:342-346.

8. Boettinger WJ, Bendersky LA, Schaefer RJ, Biancaniello FS (1988) On the formation of dispersoids during rapid solidification of an Al-Fe-Ni alloy. Metall Trans A 19: 1101-1107.
9. Silva BL, Dessi JG, Gomes LF, Peres MM, Cante MV, et al. (2017) Assessing microstructures and mechanical resistances of as-atomized and asextruded samples of Al-1 wt.\% Fe-1 wt.\% Ni alloy. J Alloys Compd 691: 952-960.

10. Dahlborg U, Kramer MJ, Besser MJ (2013) Structure of molten Al and eutectic Al-Si alloy studied by neutron diffraction. Non-Cryst Solids 361: 63- 69.

11. ShpakAP, Kunitsky YuA, Karbovsky VL (2001) Cluster and nanostructured materials. Kiev, Ukraine, p. 587.

12. Il'inskii A, Slyusarenko S, Slukhovskii O, Kaban I, Hoyer W (2002) Structure of liquid Fe-Al alloys. Mater Sci Eng A 325: 98-102.

13. Bel'tyukov AL, Menshikova SG, Lad'yanov VI (2015) The viscosity of binary Al-Fe melts in the Al-rich area. J Non-Cryst Solids 410: 1-6.

14. Maksymchuk IM, Khryplviy AA, Tkachenko VG, Frizel VV (2012) Influence of electrohydropulse treatment of melt on crystallization process and properties of magnesium alloy of Mg-Al-Ca-Mn-Ti system. Metal Science \& Treatment of Metals 4: 10-17.

15. Maksimchuk IN, Tkachenko VG, Vovchok AS, Medalovich NP, Makarenko ES (2014) The decay kinetics and thermal stabilization of the cast alloy of the Mg-Al-Ca-Mn-Ti system. Metallophysics and novel technologies 36: $1-15$.

16. Maksimchuk IN, Khriplyviy AA, Tkachenko VG, Freezel VV (2012) Regularities of nonequilibrium crystallization during electrohydropulse and magnetopulse treatments of industrial silumin AK7. Visnik UMT 1: 78-88.

17. Zolotorevsky VS, Belov NA, Glazoff MV (2010) Casting aluminium alloys. Elsevier, p. 534.

18. Piątkowskia J, Szymszal J (2009) Thermal analysis and microstructure of master alloys used for modification of silumins. Archives of foundry engineering 9: 129-132.

19. Roik OS, Kazimirov VP, Sokolskii VE, Galushko SM (2013) Formation of the short-range order in Al-based liquid alloys. J Non-Cryst Solids 364: 34-39.

20. Maret M, Pomme T, Pasturel A (1990) Structure of liquid $\mathrm{Al}_{80} \mathrm{~N}$ alloy. Phys Rev B Condens Matter 42(3): 1598-1604.

21. Du M, Songzhao Li, Rongxue L, Shujing L, Peng J, et al. (2014) Locsal structure and its change of Al-Ni alloy melts. J Molecular Liquids 200: $168-175$.

22. Mudry S, Sklyarchuk V, Yakymovych A (2008) Influence of doping with Ni on viscosity of liquid Al. J Physical Studies 12: 1601-1606.

23. Das K, Horbach J, Koza MM, Mavila CS, Meyer A (2005) Influence of chemical short-range order on atomic diffusion in Al-Ni melts. Appl Phys Lett 86(1): 011918 - 011918.

24. Beltyukov A, Ladyanov V, Sterkhova I (2019) Effect of small nickel additions on viscosity of liquid aluminum. J Molecular Liquids 296: 111764-111769.

25. Inoue A, Kimura H (2002) Fabrications and mechanical properties of bulk amorphous, nanocrystalline, nanoquasicrystalline alloys in aluminum-based system. J Light Metals 1: 31-41.

26. Grushko B, Velikanova TYa (2004) Stable and metastable quasicrystals in Al-based alloy systems with transition metals. J Alloys Comp 367(1): 58-63.

For possible submissions Click below: 